\title{
REINSERÇÃO SOCIAL: PROCESSO QUE IMPLICA CONTINUIDADE E COOPERAÇÃO
}

\author{
Eliane Ganev ${ }^{1}$ \\ Wagner de Lorence Lima²
}

\section{RESUMO}

O presente artigo propõe uma reflexão em torno do conceito de reinserção social de indivíduos que se tornaram dependentes de drogas, com o objetivo de oferecer uma contribuição na construção de políticas públicas sobre drogas capazes de fazer frente a este importante problema de saúde pública na contemporaneidade. Além dos aspectos conceituais da reinserção social, discutimos seus pressupostos e objetivos; seu contexto sempre atravessado pelas complexidades e singularidades características da dependência de drogas; aspectos tais como abstinência, riscos de recaídas, desconstrução e reconstrução de estilos de vida; o caráter multidisciplinar e a necessidade do trabalho continuado e metódico, no curto, médio e longo prazos, exigindo a cooperação de distintos agentes e sujeitos implicados nos desafios da reinserção social.

PALAVRAS-CHAVE: Reinserção Social, Dependência de Drogas, Políticas Públicas sobre Drogas, Saúde Pública

\section{INTRODUÇÃO}

O presente artigo propõe uma reflexão em torno do conceito de reinserção social de indivíduos dependentes de drogas, o qual figura comumente como objetivo e parte constitutiva das mais diversas formas de abordagem, enfrentamento, trato e tratamento da dependência de drogas, visando à sua superação.

\footnotetext{
${ }^{1}$ Doutora em Integração da América Latina (USP), Mestre em Ciências da Comunicação (USP) e Bacharel em Serviço Social. Atualmente trabalha como Docente e ex-Coordenadora do Curso de Serviço Social da Universidade Cruzeiro do Sul (UCS), pesquisadora e docente do Mestrado em Políticas Sociais desta Universidade, onde Coordena o Núcleo de Estudos e Pesquisa das Políticas sobre Álcool e Drogas (NEPPAD/UCS). Participa da Câmara Técnica da Coordenação Estadual de Políticas sobre Drogas. Email: eliane.ganev@cruzeirodosul.edu.br.

${ }_{2}^{2}$ Mestre em Políticas Sociais (UCS), Especialista e Consultor em Dependência Química e Bacharel em Geografia (FESB/SP). Atualmente trabalha como Professor e Coordenador Pedagógico da Rede Estadual de Ensino. É pesquisador do Núcleo de Estudos e Pesquisa das Políticas sobre Álcool e Drogas (NEPPAD/UCS).
} 
Isto é, no âmbito da vida de indivíduos que passaram a viver sob tal condição, a reinserção social se coloca, já desde o contexto do tratamento, como possibilidade de aqueles deixarem de reproduzir práticas que os levaram a situações de autodestruição, alienação, isolamento e/ou exclusão social, em geral configuradas quase como um modo de vida no qual o consumo de substâncias psicoativas fundiu-se como finalidade e meio de vida; tornou-se o seu centro exclusivo de interesse, colocando em risco a mera sobrevivência pessoal, e pondo de lado qualquer perspectiva de desenvolvimento das suas potencialidades ${ }^{3}$.

Desse modo, organizamos o texto presente em tópicos, começando por um exercício de explicitação de aspectos conceituais. Em seguida, discutimos os diversos elementos constitutivos dos processos de reinserção social, passando então à consideração das suas possibilidades, vistas em sua dupla dimensão, isto é: no âmbito das individualidades e na esfera das redes de apoio.

\section{ASPECTOS CONCEITUAIS}

De um ponto de vista que considera os pressupostos da reinserção social, é preciso insistir que, se falamos em tratar para reinserir socialmente indivíduos dependentes de drogas, é porque tal dependência, de algum modo, teve por consequências (para além dos aspectos meramente físicos e psíquicos): isolamento, rompimentos, desfiliação face a pessoas, lugares, circunstâncias, instituições, atividades - os quais anteriormente configuravam e organizavam as dimensões de sua vida pessoal, constituindo-se mesmo como suportes objetivos de sua identidade. Ou então, a

\footnotetext{
${ }^{3}$ O sítio do Observatório Brasileiro de Informações sobre Drogas - OBID define a Reinserção Social como "reconstrução das perdas" no contexto da exclusão social que marca as situações de dependência in: http://www.obid.senad.gov.br/portais/OBID/index.php, acesso em 22/04/2010.
} 
dependência de drogas sinalizou para uma anterior e relativa "ausência", insuficiência ou grave perturbação da construção destas dimensões fundamentais. De todo modo, resultou em profunda alienação do ser, de tal modo que as relações do indivíduo, consigo próprio e com tudo e todos ao seu entorno, tornaram-se meramente instrumentais em relação aos "três momentos" a que finalmente se resume o seu viver: refazer-se do último uso, planejar/garantir o próximo e usar. Em síntese, podemos dizer que as consequências da dependência de drogas são, elas mesmas, os pressupostos da necessidade de reinserção social.

Tal afirmação não configura um consenso, nem no campo médico, nem no acadêmico, cultural e outros, mas não aprofundaremos aqui esta discussão. Apenas explicitamos que faz parte do conceito de dependência de drogas aqui tomado como ponto de partida ${ }^{4}$, a consideração de que, via de regra, o modo de vida próprio dos processos de dependência mostra-se problemático, mesmo nos muitos casos em que os indivíduos, imersos nas lógicas de uma imperiosa autojustificação, dele fazem uma bandeira supostamente libertária. Acreditamos que a totalidade das pessoas que sofrem e provocam danos em razão do uso abusivo de substâncias psicoativas, tem o inalienável direito de vislumbrar, a partir de outras perspectivas que não as da própria dependência, alternativas de fato emancipatórias ${ }^{5}$. Cabe então perguntar no que consiste tal reinserção?

\footnotetext{
${ }^{4}$ Não nos deteremos aqui sobre o conceito de dependência de drogas, bastando afirmar que o concebemos como um fenômeno multideterminado: bio-psico-socialmente. Uma breve revisão da evolução deste conceito pode ser encontrada em Formigoni (2000).

${ }^{5}$ Para tal, as políticas públicas precisam garantir, nos serviços de atendimento a este segmento, a efetivação de intervenções que propiciem para tais indivíduos, a percepção e a decisão de conhecer e permitir-se buscar outras formas significativas de relacionar-se consigo e com o processo de produção social da vida (superando, pois, de algum modo, a lógica de lançar mão do infinito rol de substâncias e mesmo de atividades passíveis de serem convertidas em força hegemônica - obsessivas e/ou compulsivas - na condução das vidas individuais).
} 
Propõe-se aqui concebê-la como um imprescindível e transversal componente do "tratamento", entendido este em sentido amplo (para muito além de uma imediata desintoxicação, por exemplo). Pensamos num processo contínuo e multifacetado de intervenções de apoio ao indivíduo dependente de drogas, no sentido da superação do modo de vida imposto pela dependência ${ }^{6}$. Tal apoio precisa, portanto, ser extensivo também àqueles que convivem mais diretamente com tal indivíduo, estando indissociavelmente implicados nos percursos desta superação, tanto quanto o estiveram nos espinhosos caminhos da dependência.

Pode-se afirmar então que o processo de reinserção inicia-se desde o primeiro atendimento, quando o dependente busca ajuda (por iniciativa própria ou de algum modo pressionado ou estimulado por iniciativas de familiares, empregadores, amigos, ou ainda por seu estado de - má - saúde, por complicações judiciais, policiais ou outras). Ajudá-lo na superação acima indicada é uma perspectiva que deve estar presente desde o primeiro atendimento, seja qual for a sua "porta de entrada" nos sistemas de proteção social (saúde, assistência, segurança, justiça, educação e tantos outros) e deve permanecer enquanto durar o processo. E isso independe do tipo de abordagem e das estratégias que vierem a ser adotadas em cada caso específico, estendendo-se a todas elas.

Diante disso pode-se afirmar que a reinserção social é um processo contínuo e de longa duração, interdisciplinar e que demanda qualificação dos serviços de atendimento, virtualmente em todos os campos - aspectos os quais convém explicitar melhor.

\footnotetext{
${ }^{6}$ Vale lembrar a existência de inúmeras abordagens potencialmente úteis, mediante avaliação caso a caso. Ver, a respeito, a coletânea reunida por Seibel e Toscano Jr. (2000).

Revista Serviço Social \& Saúde. UNICAMP Campinas, v. X, n. 11, Jul. 2011
} 


\section{ELEMENTOS CONSTITUTIVOS DOS PROCESSOS DE REINSERÇÃO SOCIAL}

Para começar, o caráter contínuo da reinserção implica em manter-se o foco no longo prazo, em evitar interrupções ou lacunas de atendimento. Cabe lembrar o elevado número de fatores de risco e vulnerabilidade a que a dependência expõe a pessoa dependente (biológicos, psicológicos e sociais ${ }^{7}$ ), cada um dos quais exigindo intervenções específicas, mas também manutenção permanente.

Traz também como implicação a necessidade de um atendimento multidisciplinar e se possível interdisciplinar, a fim de que os diversos saberes e práticas envolvidos garantam a coesão do atendimento (para além da continuidade), não obstante algum deles considerar concluída sua intervenção - a exemplo das atenções médicas, seja sobre a desintoxicação, seja sobre complicações de saúde decorrentes de anos ou mesmo décadas de uso contínuo.

Outro aspecto do trabalho de reinserção social, aqui considerado estratégico, decorre do fato de que, em geral, todo processo (necessariamente individual e intrapsíquico) de dependência de drogas pode ter sinalizado para (e/ou necessariamente afetou) relações sociais as mais diversas (cujo necessário mapeamento é rigorosamente individual): familiares, interpessoais, profissionais, pertencimentos variados (culturais, religiosos, políticos, etc.), que também pedem atenção, para serem refeitas ou transformadas, resgatadas ou (finalmente) construídas. Tal aspecto evidencia que a desejável eliminação das situações de uso abusivo de drogas (tal como a abstinência completa) é uma variável por si só insuficiente, para que sejam alcançados os resgates ou recriações necessários (e/ou possíveis, interessantes, desejáveis, significativos) para

\footnotetext{
${ }^{7}$ Cf. detalhado no Guia Prático sobre Uso, Abuso e Dependência de Substâncias Psicotrópicas para Educadores e Profissionais de Saúde do COMUDA (Conselho Municipal de Políticas Públicas sobre Drogas e Álcool), organizado por Marques e Ribeiro (2006, p. 18).

Revista Serviço Social \& Saúde. UNICAMP Campinas, v. X, n. 11, Jul. 2011
} 
o próprio sujeito, naquelas dimensões de sua vida que ficaram comprometidas pelas consequências da sua dependência.

A título de exemplo, podemos perguntar o que significa a (mera) eliminação das situações de uso abusivo (e de suas consequências mais imediatas: intoxicação aguda, episódios de violência ou roubo, fugas) diante de um relacionamento qualquer que foi persistentemente abalado por manipulações, mentira, raiva, medo, inveja, ciúmes, ausência ou ressentimentos, ou ainda pelo abandono de rituais, atividades, compromissos e interesses comuns? Como lidar com relações interpessoais que permanecem fragilizadas ou rompidas mesmo após uma súbita (ou gradual) superação das situações de uso? Como pode o indivíduo que passou por tudo isto situar-se face ao seu próprio estilo de vida, aos projetos e objetivos aos quais descubra querer dedicar-se? Deverá manter a totalidade de seus hábitos, relações e atividades? O que pode ou deve modificar em relação ao objetivo de não retroceder à situação de dependência? Com quem poderá contar nestas reestruturações pessoais e interpessoais? Quais deveriam ser suas prioridades, o que poderá ou deverá deixar para mais adiante, frente a tantas urgências se apresentando e demandando respostas "imediatas" (porque, no mais das vezes, tardias)?

São estas algumas das questões que cercam o processo de reinserção social e que remetem, necessariamente, para dois outros elementos os quais consideramos como questões a serem claramente explicitadas, problematizadas e trabalhadas em todos os casos - respeitados os ritmos e características de cada sujeito e de cada estratégia de intervenção. Questões controversas e cercadas de complexidade, mas incontornáveis se de fato se pretende a emancipação dos indivíduos em relação às situações de dependência: a abstinência das drogas de escolha (às vezes associada a um arriscado, mas necessário uso de drogas medicamentosas que podem potencializar novos 
processos de dependência) e a prevenção de recaídas (isto é, de regressão às situações de dependência, não raro em condições ainda mais severas que aquelas que marcaram o período anterior).

Entendemos ser importante enfatizar estes dois elementos como constitutivos do processo de reinserção social, por várias razões. Em primeiro lugar, embora a dependência de drogas seja um fenômeno bem caracterizado e passível de diagnóstico a partir de um conjunto de características observáveis e mensuráveis ${ }^{8}$, é também um dado objetivo que os seus processos de desenvolvimento (e de superação) padecem de "baixa visibilidade" na vida cotidiana: em especial para os próprios usuários de substâncias psicoativas e para quem convive com estes, mas também para quem realiza a intervenção nos campos da prevenção, do tratamento e da reinserção social ${ }^{9}$. Isto porque aquele conjunto de características que definem o diagnóstico da dependência de drogas - e mais ainda o conjunto de condições que poderiam caracterizar um processo de superação ou recuperação - pode variar e ocorrer (ou não) mais ou menos lentamente em cada caso, em função de um complexo de variáveis (potencial de dependência da droga de escolha; características biopsicossociais individuais; culturas predominantes em relação ao uso de drogas - no grupo familiar, na classe social, nos grupos de pertencimento, nas políticas públicas, nos serviços de saúde e na mídia, dentre outras ${ }^{10}$ ), as quais são multiplamente interdependentes e podem potencializar umas às outras. Em segundo lugar, porque mesmo os elementos mais objetivos e específicos que

\footnotetext{
${ }^{8}$ Vide os critérios do Código Internacional de Doenças da Organização Mundial de Saúde - CID 10 para "uso abusivo" e para "dependência de substâncias", disponíveis, dentre outras fontes, em Marques e Ribeiro (Orgs.), 2006 (p. 21 e 23).

${ }^{9}$ Os campos da prevenção e do tratamento foram tratados na publicação já referida (o Guia Prático...), enquanto o da reinserção social constitui o centro da presente publicação.

${ }^{10}$ Cada qual destes fatores é objeto de uma ampla revisão de estudos feitos em todo o mundo, com foco na dependência de álcool, empreendida por Vaillant (1995). Um de seus achados metodológicos, face ao que aqui discutimos, é que tal "visibilidade" é diretamente proporcional ao tempo de observação dos estudos (VAILLANT, 1995, pág. 13).
}

Revista Serviço Social \& Saúde. UNICAMP Campinas, v. X, n. 11, Jul. 2011 
caracterizam o fenômeno e a sua superação ainda não foram minimamente incorporados aos currículos e aos cursos de formação profissional das inúmeras áreas que atuam nos serviços capazes de operar como "portas de entrada" do tratamento e reinserção social de indivíduos dependentes químicos. $\mathrm{E}$ ainda, foram incorporados de forma incipiente e contraditória pela política pública sobre drogas hoje em vigor no país ${ }^{11}$.

Sabemos que a abstinência detém a evolução do quadro de dependência química, porém, é importante salientar o aspecto crônico desta, para assim reafirmar a importância da reinserção social como ação continuada. Ou seja, uma vez reiniciado o uso de substâncias psicoativas, o indivíduo dependente perderá o controle sobre o uso, voltando mais ou menos rapidamente aos padrões de uso e de consequências biopsicossociais anteriores a abstinência - a isso chamamos reinstalação, remissão ou recaída.

Para evitar o círculo vicioso de processos de recaída (às vezes sequer caracterizados como tal, mas que impõem aos serviços de atenção um papel, a um só tempo, de retrabalho e reprodução da dependência), a intervenção dos diversos agentes precisará, ainda, complementar as estratégias mais diretamente relacionadas ao problema da superação da dependência (as quais demandam um planejamento altamente personalizado, distinto de caso para caso), com alternativas e abordagens mais genéricas e de maior fôlego, capazes de oferecer suportes objetivos ao novo modo de vida em (re)construção, além de acompanhamento e, ao mesmo tempo, fortalecimento da autonomia dos sujeitos deste processo; portanto, significativos para estes últimos.

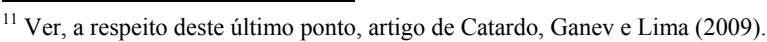
Revista Serviço Social \& Saúde. UNICAMP Campinas, v. X, n. 11, Jul. 2011
} 


\section{A DUPLA DIMENSÃO DA REINSERÇÃO SOCIAL}

A partir do que expusemos até aqui, cabe problematizar ainda outro ponto que reputamos ser essencial quando tratamos de reinserção social no contexto deste século XXI e numa sociedade desigual como a brasileira: se é fato que todo e qualquer caso de dependência de drogas gera exclusão social, é fato também que a exclusão social é fenômeno muito mais abrangente, multifacetado e complexo que o problema de saúde pública configurado pela dependência de drogas. Deste ponto de vista, a superação deste "problema menor" se transforma num grão de areia, no saco sem fundo das demandas sociais historicamente negligenciadas para gerações inteiras de excluídos (cuja imensa maioria não é dependente de drogas) por um modo de produção social da vida que permanece centrado na acumulação privada das riquezas.

Desse modo, e lembrando que não temos controle sobre as diversas variáveis macrossociais (tais como oferta de emprego, disponibilidade de recursos públicos e privados, dentre tantos outros), podemos dizer que, para o indivíduo dependente químico, há pelo menos duas dimensões da exclusão a serem trabalhadas no processo de reinserção social. A primeira é a "autoexclusão", aquela que ocorre a partir do dependente para consigo mesmo, inerente à dinâmica da dependência. E a outra é a exclusão social propriamente dita, o alijamento de milhões de cidadãos de condições mínimas de trabalho, educação, moradia, saúde, transporte e etc - sendo que, nesta segunda dimensão, a condição de dependente de drogas é fator agravante e acelerador da exclusão.

A reinserção, portanto, também pode ser compreendida a partir destas dimensões, incluindo planejadamente uma dimensão de auto reinserção, onde o indivíduo dependente, pela mudança do seu conjunto de maneiras de pensar, crenças e 
habilidades, torna-se capaz de compreender sua própria trajetória, passa a protagonizar autotransformações e adaptações que considera oportunas e significativas, toma decisões construtivas, e assim vai se fortalecendo internamente para as diversas circunstâncias de ordem mais "externa" da vida, sejam estas favoráveis ou desfavoráveis face aos seus projetos pessoais. E a reinserção efetivamente social referese mais ao conjunto daqueles fatores objetivos, menos sujeitos a qualquer controle de ordem pessoal (rede social), os quais independem de sua vontade e decisão, mas podem igualmente vir a ser objeto de avaliação e planejamento, dentro das inúmeras estratégias de intervenção que compõem o escopo do trabalho de reinserção - as quais, por seu turno, constituem o foco da presente publicação.

Assim, na dimensão que chamamos de autoinserção, as intervenções visarão a ampliar e melhorar os repertórios de habilidades do indivíduo dependente para o enfrentamento das situações de risco, sua motivação. Dizem respeito ao seu fortalecimento para a tomada de decisões, à sua assertividade, à prevenção de recaídas, autoestima, habilidades afetivas, capacidade de superar o isolamento provocado ou agravado pela situação anterior, à sua capacidade de pedir ajuda, de conhecer e falar de si mesmo. Enfim, referem-se ao desenvolvimento de todo um conjunto de informações e de capacidades para lapidar-se a si mesmo a partir de potencialidades cujos limites tornam-se mais e mais visíveis, manejáveis e flexíveis. É a instância de poder onde o indivíduo é protagonista, sujeito que pode refletir, munir-se do que considerar necessário, decidir.

Já no caso da segunda dimensão, as intervenções darão especial ênfase à família e ao conjunto de agentes sociais significativos das redes primárias de pertencimento dos indivíduos em cada caso específico (parentes, chefes ou ex-chefes, colegas de serviço, lideranças religiosas, amigos); caberá, ainda, empreender um 
mapeamento dos recursos disponíveis na comunidade (rede social), públicos e privados, tais como CAPS/AD, grupos comunitários para dependentes e familiares (as associações de "anônimos" e outros), grupos de apoio nas empresas, ONGs que ofereçam cursos para qualificação profissional e/ou melhoria da empregabilidade, escolas, trabalho voluntário, programas de moradia, a rede socioassistencial, políticas e programas culturais locais, políticas específicas para segmentos (juventude, mulher, diversidade étnica, diversidade de orientação sexual etc) e o que mais houver e for considerado útil, estratégico, significativo.

Afirmamos anteriormente que o desenvolvimento da dependência dá-se, principalmente, em meio à sociedade desigual e injusta em que vivemos (para além do grupo social primário e mais imediato, a família). Parece, portanto contraditório pretender que o indivíduo em tratamento seja convidado à reinserção nessa mesma sociedade. Contudo, é precisamente nestas formas de vida social, ainda orientadas pelo mercado e pelo consumo, onde há ampla disponibilidade de drogas e onde os apelos ao prazer sem limites são veiculados pela mídia em tempo integral, que se há de reinserir indivíduos que se perderam de si mesmos por terem, de algum modo, praticado radicalmente o que tais apelos sugerem. Como, então, lidar com tal contradição? Certamente, não subestimando sua força (no que se refere à recaída ou reinstalação) e levando-a em alta conta no trabalho cooperado de reinserção.

Vemos então que tal trabalho implica, também, um processo de explicitação e revisão em totalidade de valores e crenças, do estilo de vida pleno de hábitos arraigados que o dependente traz consigo (cuja materialização é individual, mas cuja construção é social), afim de que evite repetir os mesmos percursos com roupagens e expectativas formalmente diferentes. Suas relações com pessoas, lugares, circunstâncias e contextos, precisam ser postas em questão. Os focos deste trabalho com o indivíduo dependente, 
em que este deveria ser cada vez mais protagonista, é o desenvolvimento de uma autoconsciência capaz de protegê-lo dos apelos do mercado para o prazer; capaz de torná-lo apto a fazer escolhas na direção do aumento de sua qualidade de vida, a partir de sua própria história; de defender sua recuperação e seus interesses frente a quaisquer estímulos externos.

Contudo, mesmo no contexto de intervenções adequadas, precisamos considerar que as recaídas ocorrem; que suas consequências para o indivíduo vão variar, desde novas perdas afetivas, de confiança e de vínculos até perdas materiais, de postos de trabalho, problemas com a justiça e, no limite, riscos de perda da própria vida. A interrupção da abstinência precisa ser vista neste contexto como uma experiência a ser valorizada no sentido de uma aprendizagem para o indivíduo dependente, face à totalidade dos seus vínculos. Ajudá-lo (bem como seus familiares e outras pessoas chave mais próximas) na compreensão dos fatores responsáveis pela recaída, para que possa mais uma vez superá-la e evitar repetir os comportamentos e maneiras de pensar que o levaram a ela, são tarefas que se colocam para todos os agentes envolvidos em cada caso sob acompanhamento.

Cabe pensar ainda que a dependência de drogas, vista como um fenômeno de grupo amplia o raio de abrangência do tratamento e da reinserção, para aí incluir a família do dependente ${ }^{12}$. Dissemos anteriormente que, dentre outras metas, resgatar a funcionalidade e a qualidade de vida do dependente é uma das perspectivas na intervenção. Ora, deixarmos a família alheia a esse processo seria um equívoco, além do mais, contraproducente. Cabe, portanto incluí-la dentro do resgate da qualidade de vida

\footnotetext{
${ }^{12}$ A família vem sendo considerada como unidade estratégica de intervenção no âmbito das Políticas Nacionais de Saúde e, mais recentemente, de Assistência Social. Vide o lugar atribuído à família no próprio texto da Política Nacional de Assistência Social, de 2004 (disponível no site do Ministério do Desenvolvimento Social).
} 
perdida no processo de desenvolvimento da dependência de um de seus membros. A equipe responsável precisa estar atenta para as "recaídas" dos membros da família (em hábitos e crenças predominantes no período anterior, em geral marcados pela rigidez) tanto quanto para as remissões do indivíduo dependente. Os transtornos decorrentes do abuso de drogas possuem tal capacidade de irradiação que adoecem o grupo familiar como um todo. Há casos em que a recuperação não é bem sucedida para o indivíduo dependente, porém a orientação aos familiares promove melhoras concretas e significativas em suas vidas. Identificar os papéis vividos por cada sujeito do grupo familiar no processo da dependência pode fazer grande diferença para o próprio indivíduo dependente, que assim se vê aliviado do ônus de depositário e responsável por mazelas que de fato implicam todo o grupo. Já para os familiares, o alívio pode vir da mudança de foco, cada qual para si mesmo, em contraponto ao anterior papel de controladores do dependente, dentro do qual carregavam toda a culpa e ansiedade implícitas nessa relação. São comuns os relatos de familiares que desenvolveram dependência de medicamentos, transtornos de ansiedade nos mais diferentes graus, tentativas e consecução de suicídio, na busca por controlar as ações do membro da família dependente de drogas.

Desse modo, a recomposição dos vínculos é importante na reinserção social. Estamos falando do enfrentamento de ressentimentos e culpas, aspectos afetivos que, se desprezados, podem manter o indivíduo dependente e/ou seus afetos prisioneiros de maneiras de pensar e sentir destrutivas. 


\section{CONSIDERAÇÕES FINAIS}

Por fim, e tomando a reinserção social como um direito social, posto que pode ser colocada como uma condição derivada do direito à saúde, é possível afirmar que não há possibilidade de reinserção social efetiva sem políticas públicas que as propiciem e garantam. Nesse sentido, a formulação de questões, desde as mais "personalizadas" até as mais genéricas: o que, afinal, precisa ser superado em cada caso de dependência de drogas? A partir de quais estratégias e para alcançar quais metas? Quais são as condições necessárias e suficientes da reinserção social? Quem são os sujeitos desta construção cooperada? O que deve ou precisa estar figurado, então, enquanto política pública e o que deve ou precisa ser definido a partir das singularidades de cada território e, mesmo, de cada caso individual? Que modelos de serviços podem ser oferecidos para o segmento de indivíduos que expressa o desejo de alcançar abstinência? E para aqueles que se situam na controversa e arriscada fronteira entre a liberdade pessoal face ao uso e a perda desta liberdade, precisamente em decorrência do uso abusivo? São perguntas que podem ser categorizadas de forma a permitir que a reinserção social venha a ser efetivada desde o âmbito do privado, até os distintos níveis de decisão da esfera pública (os chamados “Três Poderes" - dos municípios até a União, os investimentos em pesquisa e em serviços, o campo da comunicação social, da educação, da saúde e tantos outros). Desse modo:

a) A partir de uma perspectiva individual, podemos nos perguntar como operar o trânsito de uma vida centrada no uso de drogas para uma vida centrada no desenvolvimento das potencialidades e desejos pessoais? Em especial levandose em conta que tal desenvolvimento, ou já se encontrava previamente comprometido a ponto de estimular a dependência de drogas, ou passou a estar 
de algum modo afetado a partir dos desdobramentos do processo da dependência?

b) A partir de uma perspectiva que tenha em mente o aprimoramento e a implantação de políticas públicas, pergunta-se: como os serviços sociais essenciais (saúde, mas também assistência social, educação, cultura, obras, habitação, comunicação social, segurança, justiça e outros) precisam qualificarse e estruturar-se especificamente, para operar de forma integrada, complementar e coerente com o objetivo de reinserção social dos indivíduos dependentes de drogas e respectivas famílias? Como o acúmulo de experiências bem sucedidas de intervenção pode ser devidamente apreciado pelo meio acadêmico-científico e multiplicado na escala das demandas existentes na contemporaneidade?

c) A partir de uma perspectiva social, pergunta-se como a Política Pública Sobre Drogas precisa, por sua vez, atravessar a totalidade das relações sociais, disseminando-se a ponto de ser apropriada, multiplicada e/ou acessada pelos principais sujeitos da reinserção social: os segmentos (internamente heterogêneos) dos indivíduos dependentes de drogas, familiares, empregadores, técnicos que operam os serviços sociais e outros campos da vida social, direta e indiretamente implicados?

Neste texto, pontuamos aspectos relativos a estas questões, os quais podem ter ênfase diferenciada conforme o tipo de intervenção realizada em cada caso, porém a reinserção social parece ser o ponto de convergência, comum às diversas formas de intervenção. Assim como não há uma única forma de intervenção que reclame para si a efetividade exclusiva para a superação da dependência química, e que o desejável para 
as políticas públicas é que sejam oferecidas de maneira variada para contemplarem as próprias diferenças entre os sujeitos, as formulações sobre reinserção social certamente refletirão essas diferenças quanto a ênfase em algum aspecto e todas entendidas como saberes que podem dialogar entre si de maneira não excludente, sendo isto imprescindível para o seu sucesso. A reinserção social passa pelo desafio dialógico de ouvir para inserir os diversos métodos de vê-la colocando como prioridade a melhora da qualidade de vida dos sujeitos envolvidos.

\section{ABSTRACT}

In this paper, we propose an analysis about the concept of social reinsertion of individuals who have become drug addicts. We want to help in planning public actions about drugs which can face this important public health problem nowadays. Apart from the conceptual aspects of social reinsertion, we hereby discuss its proposals, objectives and its context which is permanently affected by the complexities and peculiarities of drug dependency; aspects such as withdrawal, the risk of relapse, deconstruction and reconstruction of lifestyles; its multidisciplinary character and the need for continuous and methodical short-, mid- and long-term work, requiring the cooperation of those specific agents and subjects implied within the challenges of social reinsertion.

KEYWORDS: Social Reinsertion, Drug Adiction, Public Actions about Drugs, Public Health

\section{REFERÊNCIAS BIBLIOGRÁFICAS}

CATARDO, L .A. M., GANEV, E., LIMA, W. L. Notas sobre o SISNAD - Sistema Nacional de Políticas Públicas sobre Drogas. São Paulo, III HUNICON, Universidade Cruzeiro do Sul, 2008.

CNAS. Política Nacional de Assistência Social. Brasília, DF, 2004. Disponível em: http://www.sedest.df.gov.br/sites/300/382/00000877.pdf Acesso em 23/03/2012. 
FORMIGONI, M. L. O. S. Neurobiologia da Dependência de Substâncias Psicoativas. In: SEIBEL, S. D., TOSCANO JR., A. Dependência de Drogas. São Paulo: Atheneu, 2000, p. 209-18.

MARQUES, A. C. P. R., RIBEIRO, M. Guia Prático sobre Uso, Abuso e Dependência de Substâncias Psicotrópicas para Educadores e Profissionais de Saúde. São Paulo, COMUDA (Conselho Municipal de Políticas Públicas sobre Drogas e Álcool), 2006.

OBID. Reinserção Social. Disponível em:

http://www.obid.senad.gov.br/portais/OBID/index.php, acesso em 22/04/2010.

SEIBEL, S. D., TOSCANO JR., A., Dependência de Drogas. São Paulo: Atheneu, 2000.

VAILlAnt, G. E. A História Natural do Alcoolismo revisitada. Porto Alegre: ARTMed, 1999. 